\title{
A aposta na tessitura de redes como inovação do trabalho no campo sociojurídico
}

The bet on the range of networks as a way
to innovate work in the social-judiciary field

\author{
Anne Karoline Ferrari \\ Assistente social no Tribunal de Justiça do Estado do Espírito Santo/ES, Brasil. \\ akferrari@gmail.com
}

\section{Gilead Marchezi Tavares}

Professora associada do departamento de Psicologia e do Programa de Pós-Graduação em Psicologia Institucional da Ufes.

gileadmt.2014@gmail.com

\begin{abstract}
Resumo: As práticas de assistentes sociais e psicólogos no campo sociojurídico capixaba contam histórias que desvelam tanto os modos de funcionamento instituídos naquele espaço laboral, quanto provocam a desestabilização do saber/ poder daquelas categorias profissionais, descortinando as formas de resistência que têm sido forjadas cotidianamente em favor de uma postura ético-política de defesa da vida, na contramão de sua recorrente judicialização, como o investimento no trabalho em rede.
\end{abstract}

Palavras-chave: Práticas jurídicas. Assistentes sociais e psicólogos. Trabalho em rede.
Abstract: The social workers and psychologists' practice in the social-judiciary field in Espírito Santo is related to stories that both show how work is done in that space, and lead to the destabilization of the knowledge-consent of those professional categories, thus uncovering ways of resistance that have been invented in favor of an ethicalpolitical attitude defending life, on the opposite way of its repeating judging. Networking is an example of that.

Keywords: Judiciary procedures. Social workers and psychologists. Networking.

\section{Introdução}

ste artigo resulta de dissertação de mestrado nascida de indagações em
torno do que conta a história do Judiciário como um espaço laboral do
Serviço Social e da Psicologia, que emergiram a partir do meu ingresso no Tribunal de Justiça do Estado do Espírito Santo (TJES) no ano de 2012. 
A pesquisa/intervenção que originou a dissertação pretendeu discutir as práticas dos profissionais de Serviço Social e Psicologia nas Varas de Família e Sucessões do Judiciário capixaba. Na busca por alcançar tal objetivo, acompanhei as reuniões da Comissão Temática na Área de Família, constituída a partir de alterações ocorridas no regimento interno do Fórum dos Assistentes Sociais do Poder Judiciário do Estado do Espírito Santo. ${ }^{1}$

Paralelamente às reuniões, também compuseram o corpus de análise do trabalho, o registro de minhas experiências profissionais no cotidiano da Central de Apoio Multidisciplinar (CAM) de Vitória. ${ }^{2}$

O espaço das reuniões da Comissão Temática na Área de Família e da CAM de Vitória possibilitaram o registro do que Aguiar e Rocha (2003, p. 11) chamam de "múltiplos sentidos [...], desconstruindo territórios e facultando a criação de novas práticas", contribuindo para desestabilização de modos de pensar e de fazer.

A organização do diário de campo se deu pela afetação produzida pelas práticas institucionalizadas; pelas práticas derivadas das novas requisições judiciais, como a realização de visitas assistidas; pelas estratégias forjadas individual ou coletivamente em meio a rotinas de trabalho, tornando-se o registro do diálogo que mantinha comigo mesma e com os demais assistentes sociais e psicólogos do campo sociojurídico, com os demais serviços da rede formatada pelas políticas públicas do município de Vitória (e às vezes de demais municípios do estado) e com as demais categorias profissionais (professores, pedagogos, agentes comunitários de saúde, terapeutas ocupacionais, enfermeiros,

1. Criado no ano de 2010, o Fórum de Assistentes Sociais do Poder Judiciário do Estado do Espírito Santo sofreu no ano de 2013 alterações em seu regimento interno, objetivando adequar-se às transformações inauguradas no Judiciário capixaba pela expressiva ampliação do quantitativo de profissionais do Serviço Social e pela criação de cargo destinado ao exercício profissional da psicologia. A principal alteração diz respeito à composição do Fórum, que incorporou os psicólogos, passando a denominar-se Fórum dos Assistentes Sociais e Psicólogos do Poder Judiciário do Estado do Espírito Santo (Fasp).

2. As Centrais de Apoio Multidisciplinar foram criadas pela Lei Complementar n. 567/2010 e destinam-se ao atendimento de demandas originadas das Varas de Família e das Varas Especializadas em Violência Doméstica e Familiar contra a Mulher (além das Varas da Infância nas comarcas do interior do estado do Espírito Santo), sendo constituídas por profissionais de Serviço Social e Psicologia (Espírito Santo, 2010). No ano de 2014, a Resolução n. 29/2014 do TJES alterou a redação da lei complementar que deu origem às CAMs, extinguindo a exclusividade de atuação nas referidas varas, o que oficializou, por exemplo, o atendimento às demandas das Varas de Sucessões às quais os profissionais já eram apresentados. 
médicos etc.) que atravessaram meu cotidiano profissional e, assim, o campo de investigação da pesquisa.

O diário de campo, como instrumento privilegiado de pesquisa, pretendeu, desse modo, constituir um dispositivo que nos auxiliasse a produzir, ao longo de toda a experiência da pesquisa, material de registro dos eventos experimentados, observados ou compartilhados, bem como a análise das práticas, dos discursos e das posições dos participantes, bem como das relações que foram nutridas entre estes e a pesquisadora.

O diário de campo foi, ao mesmo tempo, o instrumento de produção de "dados" e o dispositivo analítico que fez emergir os analisadores das instituições em jogo nas práticas profissionais de assistentes sociais e psicólogos do TJES.

A realização da pesquisa/intervenção produziu, com o uso desse potente instrumento de fabricação de mundos, o diário de campo, narrativas que buscam trazer novas versões de histórias cotidianas para fazer proliferar sentidos/acontecimentos. Este trabalho resulta, portanto, de uma aposta metodológica de que o "exercício de pesquisar não é descolado daquilo que produz: ao inventarmos nossas pesquisas, seguir/tracejar/criar rastros de interrogações e modalidades de conhecimento, constituímos certas experiências de mundo, de subjetividade, de relações" (Moraes e Bernardes, 2014, p. 8).

Assim, orientada pelo referencial teórico-metodológico da análise institucional, a pesquisa/intervenção propôs-se à análise de uma realidade social que é constituída cotidianamente nas práticas dos sujeitos.

Buscamos amplificar, por meio da pesquisa/intervenção, o modo de compreensão das práticas do Serviço Social e da Psicologia no TJES, partindo, para tanto, das múltiplas realidades e verdades enredadas nas histórias que seu fazer profissional cotidianamente sistematiza.

Pautamo-nos na premissa de que colocar em análise a atuação desses profissionais no campo jurídico era inventar junto com eles modos de exercitar criticamente o olhar sobre o cotidiano das práticas que operam no espaço do Judiciário sob a lógica da fiscalização, do julgamento e da punição, afirmando a defesa da legalidade ao promover o efeito ameaçador do policiamento mútuo, fundamental ao funcionamento da sociedade em tempos de biopoder.

No bojo de tal conjuntura, torna-se comum a formulação de requisições aos profissionais do Serviço Social e da Psicologia, inscritos no campo socio- 
jurídico, em favor de atuações de cunho tecnicista e cientificista que possibilitem a compreensão da realidade, frequentemente auferida pelo direito a partir de avaliações e intervenções guiadas por modelos idealizados pela sociedade burguesa e, portanto, pautadas na expectativa por práticas punitivas, centradas em vieses moralizantes e disciplinadores.

Observando o maciço alargamento da importância conferida à dimensão jurídica no cotidiano das práticas profissionais, problematizar o Poder Judiciário, como estrutura de manutenção do status quo, faz-se fundamental ao desafio de efetivação dos projetos ético-políticos das referidas categorias profissionais.

Também é desafiador, nesse contexto, manter um fazer profissional que não incorpore verdades jurídicas, que representam, na maior parte das vezes, interesses políticos incompatíveis com os compromissos éticos e políticos de assistentes sociais e psicólogos.

Desse modo, partindo das histórias que assistentes sociais e psicólogos inscrevem no campo sociojurídico capixaba por meio de suas práticas, e contando uma delas, este artigo apresenta o ensaio de outro modo de atuação profissional que persegue o compromisso com a invenção de outras possíveis formas de fazer profissional, capazes de subverter, em alguma medida, a lógica de um saber-poder autossuficiente que historicamente tem exilado seus profissionais na crença de que constituem uma classe de especialistas distintos, independentes e, até mesmo, superiores aos demais.

Nesse sentido, a aposta na tessitura de redes de atuação interdisciplinar e intersetorial pareceu corresponder, ao longo da pesquisa, à construção de um instrumento potente, capaz de impulsionar a configuração de respostas aos profissionais do campo jurídico diante da latente incompatibilidade entre a atuação que lhes é requisitada e os compromissos ético-políticos do Serviço Social e da Psicologia.

\section{A concepção de rede}

A concepção de rede emerge do campo de atuação profissional na política pública de assistência social e encontra-se diretamente correlacionada à 
instauração da seguridade social ${ }^{3}$ a partir do texto constitucional brasileiro de 1988.

Estabelecendo garantias de acesso à saúde, assistência e previdência social, a seguridade social inaugura o paradigma de direito às políticas públicas, suplantando a condicionalidade dos seguros sociais e comprometendo-se com a proteção social no contexto de uma sociedade capitalista, que tende à mercantilização de direitos, e, portanto, à progressiva transformação do cidadão em cidadão consumidor (Fagundes e Nogueira, 2008).

A inauguração das premissas de integralidade e intersetorialidade, inerentes à concepção e ao funcionamento da seguridade social, parece não haver contado, no entanto, com um campo político-econômico promissor ao seu desenvolvimento, já que nesse cenário adverso, de mercantilização das demandas sociais, as políticas de proteção social revelaram-se fragmentadas, especialmente no que se refere a sua gestão e financiamento.

Fagundes e Nogueira (2008) evidenciam que, apesar do exposto, a preocupação em compor uma dimensão técnico-operativa que oferecesse concretude aos princípios organizativos da proteção social emergiu posteriormente e de forma progressiva, tanto no campo da saúde quanto no da assistência, conferindo contornos à indispensável primazia por integralidade nas respectivas políticas.

Nesse sentido, os autores destacam que

um dos mais conhecidos sentidos atribuídos ao atendimento integral refere-se ao reconhecimento do todo indivisível que cada pessoa representa, trazendo como consequência a não fragmentação da atenção, reconhecendo os fatores socioeconômicos, políticos e culturais como determinantes da saúde e da proteção social e, principalmente, sugerindo um modelo integral de atenção. (Fagundes e Nogueira, 2008, p. 4)

Pensar um modelo de atenção integral nas políticas públicas destinadas à proteção social pressupõe ainda o favorecimento da intersetorialidade,

3. A seguridade social é definida em lei como um conjunto integrado de ações de iniciativa tanto dos poderes públicos quanto da sociedade, que pretendem assegurar os direitos à saúde, à previdência e à assistência social (Brasil, 1991). 
compreendida como a articulação das próprias políticas setoriais e dessas com a complexa rede que abrange outras organizações e seus respectivos serviços.

Torna-se fundamental, para Fagundes e Nogueira (2008), que no bojo desse processo também se prime por práticas profissionais articuladas, ou seja, pela interdisciplinaridade, garantindo, assim, "uma atuação intersetorial institucionalizada não só no nível discursivo como também no da ação" (p. 7).

Compor as premissas da integralidade e da intersetorialidade exige, desse modo, a superação de construções históricas no modelo da administração pública, organizada em estruturas verticais e estanques, bem como das rotinas burocráticas por ela empreendidas.

Nesse contexto, Bourguignon (2011) destaca a constituição do trabalho social em rede como estratégia promissora ao alcance de alternativas bem-sucedidas de resposta às demandas sociais, já que se compromete com a busca por integralidade e intersetorialidade de organizações, serviços e programas, profissionais, informações e ações. Portanto,

O termo rede sugere a ideia de articulação, conexão, vínculos, ações complementares, relações horizontais entre parceiros, interdependência de serviços para garantir a integralidade da atenção aos segmentos sociais vulnerabilizados ou em situação de risco social e pessoal. (Bourguignon, 2011, p. 4)

Estabelecer o trabalho social em rede oportuniza, para a autora, a inauguração de um novo modelo de gestão das políticas públicas, possibilitando a superação da fragmentação e do paralelismo de ações, a descentralização de informações e decisões, a superação de divergências sobre a atuação de cada componente da rede, a flexibilização de hierarquias e o fortalecimento do sujeito alvo da atenção das políticas públicas.

Desse modo, o trabalho em rede desafia os profissionais nele envolvidos a se abrirem para a construção de espaços articulados propícios à ampliação de debates, ou seja, à interlocução entre os diversos executores de políticas previstas em diferentes serviços e programas, assim como a formatação de agendas conjuntas em que objetivos e ações sejam compartilhados.

Carlson e Pinheiro (2013) lembram que, apesar de aparentemente presumível no cotidiano dos profissionais da assistência social e demais políticas 
públicas, já que perfeitamente alinhado à dimensão ética de suas atuações nesse campo, o trabalho em rede revela-se muitas vezes como um ideal inatingível, um discurso utópico, uma "sobretarefa" ou mesmo um desrespeito ao trabalho profissional individual.

Para as autoras, a manutenção de práticas "antigas e autocentradas", inadequadas à construção de ações baseadas na reciprocidade, como princípio norteador ao favorecimento da composição de redes, torna indispensável considerar que sua preservação está diretamente relacionada ao exercício do saber/ poder inerente às atuações profissionais.

A superação desse aspecto vincula-se aos demais parâmetros estabelecidos como requisitos ao trabalho em rede, exemplificados pelos autores pelas orientações propostas pelo Ministério de Desenvolvimento Social e Combate à Fome, aos serviços da assistência social, nas quais é enfatizada, entre outros pontos, a necessidade de conhecimento do trabalho de cada instituição e seu fazer profissional; a disponibilidade para negociação e diálogo permanente, bem como para a flexibilização de processos e fluxos de trabalho; o compromisso com o fazer coletivo e o empenho em impulsionar conexões, como reuniões, encontros, contatos periódicos.

Essas considerações dizem do esforço pela integralidade e intersetorialidade de ações no campo das políticas de seguridade social e fazem pensar o modo pelo qual os profissionais de Serviço Social e de Psicologia do Poder Judiciário articulam-se na composição do trabalho em rede e às redes já compostas em seus territórios de atuação. Nessa perspectiva, faz-se imprescindível o resgate do enunciado de suas práticas nesse espaço de trabalho.

Historicamente convocados a reforçar dimensões disciplinadoras e moralizantes a partir de suas atuações no Judiciário, assistentes sociais e psicólogos são investidos, nesse campo, da prerrogativa de peritos, ou seja, de especialistas que versam, a partir de um exame de caráter técnico, conteúdos relacionados às suas respectivas áreas de formação (Fávero, 2007).

De acordo com Fávero (2007), a sistematização desses conteúdos na produção de documentos, como relatórios, laudos e pareceres, constrói um saber que abriga, potencialmente, a construção de uma verdade, na medida em que "pessoas são examinadas, avaliadas, suas vidas e condutas interpretadas 
e registradas, construindo-se, assim, uma verdade a respeito delas" (Fávero, 2007, p. 28).

Para o Conselho Federal de Serviço Social (CFESS), é esse o apelo da cena contemporânea que referenda o Judiciário como lócus privilegiado de resolução de conflitos inerentes às relações sociais, colocando no cotidiano dos assistentes sociais inscritos profissionalmente nessa instituição a "interferência na elaboração dos instrumentos privativos da ação profissional, determinando um desafio à efetivação do projeto ético-político" (Atuação..., 2014, p. 14), já que se encontram imersos em uma lógica de redução da análise de situações sociais a ritos processuais.

Toda essa conjuntura auxilia na compreensão sobre a presença de antagonismos e relações hierarquizadas na produção dos discursos inerentes à multiplicidade de atores vinculados a esse campo laboral, o que dificulta e até mesmo impossibilita a configuração de "redes internas".

Carlson e Pinheiro (2013, p. 109) referem-se às "redes internas" como a formatação de trabalho em rede que

pressupõe um processo de interação e disponibilização para compartilhar afeto e conhecimento. A formação da rede interna, nessa visão, passa por compartilhamento, intercomunicação, inclusão e interesse comum dos sujeitos. É fundamental para ações de construção coletiva, o que aponta para a qualificação permanente da metodologia do trabalho social. Essa dimensão humana da rede é fabulosa e faz crer que, muito mais do que nós, ela é formada por laços - laços de parceria e afeto entre colegas que se debruçam, sofrem e empreendem esforços pelas mesmas questões. Vista por esse prisma, não deixa de ser também um exercício de solidariedade e estratégia de sobrevivência profissional, já que, na mesma proporção do conhecimento técnico, nosso trabalho exige estrutura emocional fortalecida como condição para ações qualificadas.

A dificuldade e/ou impossibilidade de configuração do trabalho em rede entre os atores/profissionais do Judiciário atinge não apenas as relações nutridas entre assistentes sociais e psicólogos e os operadores do direito, mas também as relações que eles estabelecem entre si, comprometendo o exercício de práticas interdisciplinares. 
Para as autoras, muito mais que entraves burocráticos e rotinas de sobrecarga de trabalho, as adversidades que fragilizam essa proposição de atuação profissional devem-se ao sentido que cada profissional atribui a essa aposta, o que é indissociável dos egocentrismos nutridos e das pretensões de conservação de seu saber/poder.

A frágil relação que assistentes sociais, psicólogos e operadores do direito compõem entre si no Poder Judiciário parece ser, de maneira geral, estendida às demais organizações, seus serviços e programas, bem como aos atores/ profissionais que atuam em favor da garantia da proteção social e da execução das políticas públicas, o que, de certo modo, é atrelado e reforçado pelo argumento da independência dos poderes a que se encontram respectivamente subordinados.

A divisão de poderes que rege a organização do Estado brasileiro regimenta as atribuições inerentes a cada um deles pensando-os como instâncias autônomas (para impor limites à possibilidade de uma concentração indesejada de poder), mas tendo seus funcionamentos submetidos a uma lógica de interdependência e concordância entre si.

O que se observa, contudo, nas relações estabelecidas entre Legislativo, Executivo e Judiciário (especialmente as correspondentes aos dois últimos) é a construção de posições polares e pouco amistosas, flagrantes na relação de afastamento que caracteriza a atuação de seus servidores, entre eles assistentes sociais e psicólogos, obstaculizando a configuração de práticas híbridas e, portanto, a noção de integralidade e do trabalho em rede.

Dito de outra forma, é comum que inexistam "redes internas", constituídas entre profissionais do Serviço Social e da Psicologia do campo sociojurídico, bem como a tessitura de redes entre estes e os profissionais vinculados à execução das políticas públicas, aspecto que impossibilita compreensões coletivas sobre o sujeito/usuário que se apresenta como alvo de suas ações, ainda que essas pareçam compartilhar os mesmos ideais.

Desse modo, em geral são estabelecidas atuações profissionais e organizacionais configuradas de maneira estanque e alicerçadas em tiranias acadêmicas, o que as torna fatalmente restritivas e simplificadoras, impedindo novas 
aberturas à comunicação e às trocas permanentes, indispensáveis ao alcance da integralidade de políticas e de ações.

Abdicar de um trabalho em rede diz, além disso, da falta de credibilidade atribuída aos serviços, suas organizações e seus profissionais, podendo inclusive, e não raro, culminar em desqualificações, desconfianças sobre competências técnicas e reafirmações do saber/poder que lhes é conferido, especialmente o saber/poder de assistentes sociais e psicólogos do Poder Judiciário por sua condição de especialistas peritos.

Esse contexto desvela, portanto, a necessidade de clareza sobre a impossibilidade de ser e fazer tudo no campo jurídico, aceitando a inevitável dependência de outras organizações e profissionais para a construção do profissional sociojurídico.

Além disso, é preciso compreender e respeitar o fato de que a ação dos serviços a que esteve ou está vinculado o sujeito que se apresenta ao Judiciário produz afetos e sentidos que inevitavelmente comparecerão em seu encontro com a nova instituição e seus atores.

Furtar-se ao trabalho em rede no Judiciário pressupõe uma independência que de antemão sabe-se não deter pelo próprio perfil/característica de sua prática nesse campo laboral, que se pretende rigidamente delimitada pelos prazos processuais e que se acredita estar encerrada com a emissão de documentos correlatos à sua atuação e à consequente expectativa de resolução do mérito, ${ }^{4}$ o que, no entanto, não é compatível com a vida dos envolvidos, que seguirá sobre a reverberação indefinida das decisões judiciais, dos despachos e sentenças para os quais contribuem as produções documentais do Serviço Social e da Psicologia.

Torna-se imprescindível, desse modo, a compreensão sobre a inter-relação inerente à experiência dos sujeitos no contexto do Judiciário e os efeitos sobre suas vidas, um processo dinâmico e sem roteiro prévio que pode encontrar na disponibilidade ao trabalho em rede uma prática comprometida com a proteção social, a garantia de direitos e a expansão da vida.

4. Expressão jurídica que indica a dissolução do conflito que originou o processo, correspondendo, portanto, a sua extinção no Judiciário. 


\section{A composição de redes no campo sociojurídico capixaba lou uma narrativa possível!!}

Eram seis os protagonistas dessa história. Três mulheres e três homens que constituíam entre si duplas de irmãos consanguíneos. Suas trajetórias de vida mantinham muitos aspectos em comum.

Estavam todos em torno de sua quarta ou quinta década de vida e até esse momento já haviam experimentado incontáveis dramas protagonizados por seus diagnósticos de transtornos mentais.

O percurso de seus adoecimentos registrava, invariavelmente, a adoção de condutas terapêuticas centradas na supermedicalização e na institucionalização, destinadas, em regra, a sujeitos incapacitados como eles.

Sua condição de incapacidade também lhes havia imposto a interdição civil. ${ }^{5}$ Todos os seis, em algum momento de suas histórias, haviam sido judicialmente atestados como inábeis, de maneira absoluta ou relativa, para exercer de forma autônoma os atos da vida civil.

A requisição de suas interdições esteve, frequentemente, vinculada à necessidade de seus familiares de lhes resguardarem os direitos previdenciários a que faziam jus por sua incapacidade para a vida e para o trabalho.

Não era raro que também percebessem valores monetários originados do falecimento dos pais, seus cuidadores e curadores, ${ }^{6}$ um evento que se por um lado lhes gerava uma via indenizatória, por outro lhes furtava os principais responsáveis por seu cuidado e proteção, inaugurando a necessidade de substitutos na execução de tais encargos.

As substituições de curatela que os grupos de irmãos experimentaram foram fatalmente acompanhadas pela requisição judicial e pela produção de estudos ou perícias sociais capazes de avaliar a preservação, ou não, de sua

5. Instituto jurídico destinado às pessoas absoluta ou relativamente incapazes de exercer por si próprias os atos da vida civil em decorrência de enfermidade ou deficiência mental. Também destinada aos ébrios habituais, aos viciados em tóxicos, aos excepcionais e aos pródigos (Brasil, 2002).

6. Instituto jurídico que impõe a alguém, preferencialmente um familiar, o encargo de gestão dos bens e do cuidado da saúde, ou seja, a proteção de outro alguém atestado como incapaz. 
proteção e da garantia de seus direitos no curso do exercício da nova curatela que entraria em vigor.

Se a expectativa da requisição judicial era tão somente a de que se pudessem forjar mecanismos de verificação da aptidão ou inaptidão do curador substituto, evidenciando sua idoneidade, ou a ausência dela, para administrar o cuidado de saúde e o patrimônio financeiro dos interditados, o curso da elaboração dos estudos ou laudos e seus respectivos pareceres revelava que os grupos de irmãos abrigavam outros pontos de contato em suas trajetórias pessoais, descortinando eventos que demandavam mecanismos de intervenção.

Ao longo dos procedimentos metodológicos que eram elegidos para a condução do processo, o exercício da curatela - seja a dos pais ou a de familiares substitutos - sobre os seis se revelava permeado por incontáveis violações de direitos.

A assistência financeira, compreendida pela administração de seus bens e/ou patrimônios, bem como a assistência à saúde constituíam aspectos permanentemente negligenciados.

A negligência abrigava a experiência do confinamento em condições adversas e degradantes, que ultrapassava o histórico de suas internações manicomiais e era sutilmente reproduzida em seus espaços domésticos.

Bem menos sutil era a aposta, maciça e exclusiva, de que suas limitações eram absolutamente incapacitantes, o que lhes expropriava o contato e a manipulação de objetos potencialmente cortantes, o uso da eletricidade, o consumo de água (para ingestão ou para banho), a independência para qualquer atividade sobre a qual demonstrassem possibilidades de realização, as preferências e as vontades.

Nesse contexto, a rua, compreendida pelos curadores como sinônimo de fuga, revelava em suas histórias um cenário de múltiplas facetas: a de abrigo e proteção, a de exploração de suas debilidades e a de risco ou de potência de vida.

Para as mulheres tornava-se o espaço das experiências e/ou violações sexuais, inaugurando, sucedendo ou coexistindo com as práticas incestuosas de seus domicílios, tornando-as mães e, ao mesmo tempo, confiscando-lhes a maternidade. 
Entre os homens, ainda que para alguns os tornasse alvo de cooptação em atividades criminosas por sua inimputabilidade, a rua parecia mais complacente.

O fato era que suas vivências, tanto as de rua quanto as do espaço doméstico, sob o olhar dos especialistas, lhes impunham incontáveis violências, tornando-os elegíveis como usuários dos serviços especializados das políticas públicas de assistência social e de saúde.

Diante desse fato, parecia pertinente ao técnico do Judiciário que, antes de emitir qualquer estudo ou laudo, estabelecesse um contato com os respectivos profissionais já vinculados às histórias dos interditados.

Os contatos realizados deixavam evidentes as incertezas e objeções que os profissionais dos serviços sustentavam diante da atuação do Judiciário, já que historicamente os especialistas sociojurídicos prezavam pela conservação de seu saber/poder e da especificidade de suas atuações, locais e situadas, demonstrando pouco ou nenhum interesse em estabelecer trocas com os especialistas de outras instâncias e pouca habilidade para construir práticas interdisciplinares e intersetoriais que se sobrepusessem à mera obtenção de informações.

Nesse ponto do enredo estávamos, então, frente a três processos judiciais, três famílias acompanhadas pelos serviços da política de assistência social e seis pacientes dos serviços das políticas públicas de saúde, espaços nos quais todos seus especialistas carregavam brava e solitariamente suas descobertas, impressões e crenças.

E assim, mas não sem muitas dificuldades, as seis trajetórias individuais foram conduzindo as trajetórias de atuação dos vários profissionais nelas envolvidos em algum momento, de modo a construírem disponibilidades e articulações em favor de práticas interdisciplinares e intersetoriais, que impulsionaram análises e encaminhamentos conjuntos.

Chegava-se, ou tentava-se chegar, a um consenso sobre a necessidade de subsidiar os processos judiciais não apenas com considerações técnicas sobre o exercício das curatelas em vigor, mas, essencialmente, sobre a urgência em se proporcionar as intervenções recomendadas à proteção dos interditados, assim como de suas famílias, pelo conjunto dos profissionais que já os acompanhavam.

E foi então que se optou pela realização de estudos ou laudos por intermédio dos quais fosse possível contemplar tais aspectos e que, além disso, 
garantissem a continuidade de acompanhamento de interditados e curadores pelo tempo necessário também no Judiciário, tornando preciso, então, contar com novos atores nessa história: os operadores do direito.

Desta forma, lançou-se mão novas construções coletivas, nas quais entravam em cena os promotores de justiça e os magistrados, capazes de legitimar as recomendações propostas ao convertê-las em decisões judiciais, também responsáveis por manter em curso, pelo tempo necessário, os processos em questão.

Mas, como não bastavam apenas as garantias legais à viabilização dos direitos, obstaculizados ou suprimidos aos interditados, iniciava-se a construção de uma nova história: a de composições coletivas entre os profissionais do Judiciário (incluindo os operadores do direito), os da assistência social e da saúde, e os familiares, curadores e interditados.

Movidos pela expectativa de transpor práticas de disciplinamento, culpabilização e criminalização dos curadores, apostando na possibilidade de estar com eles, assim como com os grupos de irmãos, pelo tempo e naquilo que demandassem, enveredávamos por uma história que estava só começando a ser contada.

E assim, mesmo longe do fim das muitas histórias existentes em cada uma destas aqui reunidas, já éramos todos, em algumas cenas e em determinados momentos, protagonistas. Parecia, então, que não eram mais seis. Talvez agora fôssemos muitos.

\section{0 que a aposta na composiçã̃o de redes descortina}

Pensar a possibilidade de construção de atuações transversais e híbridas, ou seja, a possibilidade de composição do trabalho em rede pelo Poder Judiciário, especialmente com o Poder Executivo, prescinde de uma compreensão crítica dos processos de trabalho, rotineiros e burocráticos, nesse campo.

A atuação de assistentes sociais e psicólogos no campo sociojurídico os converte em agentes de intervenção da esfera estatal sobre o espaço doméstico e, portanto, sobre os conflitos privados. 
Considerando esse aspecto, Iamamoto (2010) chama a atenção para as situações-limites que, de maneira geral, abrigam os processos judiciais nos quais é requisitada a atuação dos especialistas, e atenta para o fato de que "a busca da proteção judicial tem lugar quando todos os demais recursos são exauridos" (p. 283).

Propõe, assim, uma compreensão segundo a qual o que conduz os indivíduos a procurar a intermediação de um agente externo ao judicializar aspectos de suas vidas é, frequentemente, o anseio de que aquele seja capaz de intervir ou apontar alternativas sobre conflitos para os quais se julgam ineficazes para resolver.

Para a autora, tal compreensão descortina duas possíveis vias ao fazer profissional dos assistentes sociais nesse terreno. A primeira corresponde a uma atuação comprometida com a expectativa do Estado de que se tornem a extensão de seu braço coercitivo, o que pode ser identificado pela adoção de práticas autoritárias e burocráticas que se permitem ferir o direito à privacidade dos indivíduos em conflito.

A segunda via descrita por Iamamoto (2010) indica uma conduta profissional que se pretende alinhada com a oferta de acesso aos seus direitos, utilizando-se para tanto da produção de estudos, laudos e pareceres, tornando-os capazes de oferecer ao juiz a possibilidade de compreensão crítica sobre a vida desses indivíduos, aspecto fundamental para as decisões que lhes são privativas.

Nessa medida, adverte que a competência legal para o julgamento e a decisão sobre os conflitos apresentados nos processos constitui prerrogativa exclusiva dos juízes, o que torna o assistente social, na condição de especialista perito, legal e institucionalmente seu subordinado.

Para a autora é preciso, no entanto, não perder de vista que o especialista dispõe de relativa autonomia técnica e ética para o exercício de suas atribuições, o que possibilita que sua subordinação não corresponda a uma subalternidade profissional.

Iamamoto (2010) considera indispensável a esse deslocamento o reconhecimento das condições e relações de trabalho que irão determinar o grau de autonomia profissional, requisito indispensável tanto ao estabelecimento de novas práticas no campo sociojurídico, quanto à afirmação de seu projeto ético-político. 
Considera, ainda, que as inovações sobre a atuação profissional, historicamente constituída nesse espaço laboral, compõem uma afirmação de lutas empenhadas em "projetar e forjar formas de resistência e de defesa da vida" (Iamamoto, 2010, p. 268; grifos da autora).

Entre as possibilidades inovadoras, aponta a composição com as redes interinstitucionais de serviços, estaduais e municipais, o que possibilita aos trabalhadores do campo sociojurídico a participação em programas e projetos executados pelos órgãos competentes e contribui para a abertura a um fazer coletivo.

De acordo com Iamamoto (2010), é preciso que o assistente social, atuando como especialista no Poder Judiciário, tenha clareza que frente à natureza da instituição em que se encontra inserido não irá atuar diretamente com a dimensão "prático-interventiva" junto aos indivíduos sobre os quais recairá sua atividade de especialista perito.

A atuação em rede pode contribuir, nessa medida, para uma contestação do “caráter 'policialesco' ou do tom repressivo que historicamente impregnou os inquéritos sociais" (Iamamoto, 2010, p. 289), ao manter os assistentes sociais do campo sociojurídico afilados ao trato das inúmeras expressões da questão social, ${ }^{7}$ na medida em que os articula aos demais poderes de Estado responsáveis pela estruturação e implementação das políticas públicas.

Para Iamamoto (2010, p. 294),

É necessário extrapolar o universo jurídico para melhor entendê-lo como um braço do poder do Estado, que tem a função de codificar as relações sociais e arbitrar conflitos, mas cuja elucidação é tributária da compreensão da trama da vida em sociedade, fonte dos reclamos e terreno sobre o qual se materializa o atendimento efetuado no âmbito do Poder Judiciário. (Grifos da autora)

Do contrário, tende-se a impregnar-se pelo "éthos da burocracia" do Poder Judiciário, que impõe permanentemente a seus agentes o esforço para constituir

7. Para Iamamoto (2010), a questão social é resultado do modo de organização da sociedade capitalista e corresponde ao conjunto das desigualdades sociais por ela engendradas, expressando-se nas desigualdades econômicas, políticas, culturais, de gênero, ético-raciais, entre outras. 
um "saber sistemático" comprometido com a verdade e manifesto no segredo. É o segredo o responsável por sua competência, pelo caráter fechado da burocracia judiciária e pela hierarquia de saber que torna seus peritos superiores aos trabalhadores e especialistas dos demais poderes (Iamamoto, 2010).

Desse modo, torna-se imprescindível subverter em alguma medida as imposições do saber burocrático no campo sociojurídico em favor de que se materialize a indispensável articulação com os recursos sociais administrados pelo Poder Executivo, capaz de ofertar retaguarda aos encaminhamentos comprometidos com a defesa da vida indicados nos estudos, laudos e pareceres.

Essa premissa serve de apoio à instalação de um novo modo de gestão das rotinas burocráticas no campo sociojurídico, permitindo a construção de alternativas às práticas instituídas, como conta a história que abre este capítulo.

A aposta em deslocar a mera verificação dos registros sobre a história dos grupos de irmãos nos serviços da assistência social e da saúde em favor da produção de formas compartilhadas de compreensão e intervenção sobre suas trajetórias de vida tornou possível estabelecer novas conexões, que, como apontam Vasconcelos e Morschel (2009), impulsionaram "andares outros" e "andar com os outros".

Para as autoras, a desnaturalização dos modos de pensar e praticar, estranhando o que parece óbvio, problematizando a realidade e encarnando novas práticas, possibilita "a invenção de outras formas de viver, conviver, trabalhar, produzir, compondo outros cenários, subjetividades e cuidados" (Vasconcelos e Morschel, 2009, p. 732).

Trata-se do desafio de duvidar de nossos próprios domínios de referência, fomentando

análises sobre a dinâmica de relações, de poderes, de práticas, de significações, de afetos que permeiam o estabelecimento analisado, colocando-as a serviço de todas as pessoas aí situadas, conferindo-lhes, assim, meios para pensarem sobre sua função e funcionamento, aliando-se a eles na análise dos ranços institucionais e problemas organizacionais e na subsequente abertura dos sentidos, construção de redes e de práticas inéditas, discursivas e não discursivas. (Vasconcelos e Morschel, 2009, p. 730) 
As redes forjadas entre Judiciário e Executivo ao longo da atuação sobre as seis histórias judicializadas fez incrementar rotinas, como a de reuniões para o mapeamento das questões imbricadas naquelas histórias, oportunizou a troca de análises e o estabelecimento de pactos de cooperação entre os profissionais em favor do alcance dos objetivos pretendidos e permitiu que processos de trabalho pouco usuais para o campo sociojurídico fossem instalados, como a realização conjunta de atendimentos e visitas domiciliares.

Estivemos, portanto, diante da desnaturalização dos protocolos, do usual emprego dos instrumentos técnico-operativos e das recomendações burocráticas gerenciais, abrindo-nos à invenção de novas práticas, livres de aprisionamentos e homogeneizações.

É preciso ter claro, como destacam Vasconcelos e Morschel (2009), que não se tratou, contudo, da "composição de paisagens estáveis, e sim sequências cênicas instáveis, belicosas, atravessadas por lutas em torno da imposição de práticas, inclusive discursivas" (p. 730), que manteve aberto um campo de infinitas possibilidades mediadas por disponibilidades e indisponibilidades, mantendo todos frente ao que ainda estava por vir.

Interessava aos diversos profissionais inscritos nessa composição de redes Judiciário/Executivo interferirem nos espaços ocupacionais a que se vinculavam, resistindo a seus princípios de burocratização e habitando-os de novos modos: movimentando-os, aquecendo-os e produzindo "pequenas revoltas diárias", como sugerem Vasconcelos e Morschel (2009).

Construía-se um modo de fazer que, conforme as autoras, circula sempre na fronteira e nas margens dos saberes e das práticas institucionais, tecendo um terreno de porosidade em que se pode observar "práticas e saberes que aceitam arriscar suas vidas a fim de se imiscuir na vida, de produzir vida, de impregnar e interferir concretamente na vida cotidiana, de atualizá-la" (Vasconcelos e Morschel, 2009, p. 730).

Assistentes sociais, psicólogos, terapeutas ocupacionais, médicos, enfermeiros, agentes comunitários de saúde traçavam alternativas pelas quais passariam a deslocar suas posições e expectativas previamente constituídas em favor da construção de possíveis soluções a serem alcançadas a partir do estabelecimento de uma prática em comum. 
Sobre tal aspecto, torna-se pertinente recuperar as reflexões de Iamamoto (2010) acerca da necessidade de desmistificar que o trabalho pautado no estabelecimento de práticas coletivas, desenvolvendo ações coordenadas, conduza a uma diluição das particularidades e competências profissionais.

Para a autora, são as práticas coletivas que permitem atribuir uma "unidade de diversidades" que demarca atuações interdisciplinares, como as que o trabalho em rede pressupõe, à medida que é a partir da formação e da capacidade teórico-metodológica de cada especialista envolvido que se torna possível descortinar os nexos existentes na situação sobre a qual se debruçam e dispor de múltiplas habilidades para realizar as ações propostas.

Tal produção de "zonas de interferência" inerente às redes que são colocadas em funcionamento corresponde, para Vasconcelos e Morschel (2009, p. 734),

a uma aposta que incide no fazer, no investimento em zonas problemáticas para as quais não encontramos respostas em nossos repertórios, nem mesmo em nossas cartilhas - ainda que estas nos forneçam pistas - arrancando-nos de nossas seguranças e nos impelindo a construir novos itinerários.

As histórias dos grupos de irmãos contam desse desenraizamento dos saberes/poderes dos diversos especialistas a eles vinculados frente à complexidade de suas trajetórias pessoais, atravessadas pelo adoecimento mental, pela idealização de modos de cuidado e da família protetora, pelas questões de gênero, pela vivência em rua.

A aposta na produção e no fortalecimento de espaços coletivos de atuação frente à multiplicidade de demandas descortinadas por essas histórias correspondeu à possibilidade de ampliação e fortalecimento de seu cuidado em saúde mental, de suporte e apoio a seus cuidadores e de proteção de seus direitos.

A promoção de articulações em tal contexto não se restringiu às parcerias intersetoriais, estendendo-se aos grupos de irmãos e suas famílias cuidadoras como estratégia comprometida com um modo de intervenção que se revelasse capaz de transpor relações de dominação, correspondendo a práticas forjadas no "entre estabelecimentos, no entre serviços, no entre usuários" (Vasconcelos e Morschel, 2009, p. 730). 
A tessitura das redes, especialmente a estabelecida entre serviços e usuários, significou trilhar um caminho de encontros e desencontros inerentes às assimetrias de saber/poder presentes, que encontravam, no entanto, ressignificação na medida em que eram alcançadas práticas de corresponsabilização que fomentavam a autonomia de todos os atores em cena.

Para Benevides e Passos (2005), esse cenário corresponde a uma potencialização das redes articuladas e se revela diretamente proporcional ao grau de abertura que os atores se permitem ao tomar decisões e ao inventar novos modos de produzir realidade.

À multiplicidade de realidades advindas das diversas experiências de trabalho acresciam-se as realidades forjadas pela trajetória de vida dos irmãos e suas famílias, que impunham o desafio de construir novos sentidos ao adoecimento mental, às possibilidades e limitações que são impostas a cada um dos seis, ao cuidado de saúde que reivindicam, aos direitos que lhes são assegurados.

As redes estabelecidas entre serviços e usuários eram desafiadas, nessa medida, a sobrepor o acúmulo de atividades rotineiras, legitimar a transversalidade de atuações em organizações iminentemente hierárquicas, em especial o Judiciário, e apostar no protagonismo de atores sobre os quais recai, como observam Falk, Ramos e Salgueiro (2009), pouco reconhecimento e visibilidade.

Tornou-se preciso resistir a uma perspectiva tecnocrática e afirmar uma perspectiva ético-político-afetiva que sustentou a desestabilização de modos de fazer, percebidos como naturais e necessários, produzindo, como apontam Vasconcelos e Morschel (2009), redes quentes de debate e produção.

Para as autoras, o que contribui para que as redes tornem-se quentes são os movimentos subterrâneos das práticas diárias comprometidas com a potência da vida capazes de sacudir as instituições e suas burocracias com a produção de novos mundos e sentidos possíveis.

\section{Consideraç̃ões finais}

Narrar histórias de vidas atravessadas pela intervenção do Poder Judiciário, braço do Estado a quem compete a sentença sobre suas dinâmicas conflituosas, possibilitou um olhar sensível para cenas em geral desfocadas pela 
sobreimplicação nas tarefas cotidianas de assistentes sociais e psicólogos trabalhadores daquele espaço laboral.

A atuação desses profissionais, frequentemente pautada pelo regime de urgência dos prazos processuais, pelas relações hierárquicas extremamente enrijecidas, pela incorporação de discursos e procedimentos de disciplinamento, não raro tem conduzido a práticas cristalizadas, "àquelas adotadas de forma naturalizada, sem pensar nem nos movimentos que as produziram, nem nos efeitos que produzem e, nessa medida, inibem novos espaços de atuação" (Nascimento e Sheinvar, 2007, p. 153).

Demarca-se, nesse sentido, a necessidade da permanente interrogação do que temos produzido e afirmado com nossas práticas nesse espaço: elas têm efetivado um compromisso ético-político de expansão da vida, ou abrigam, ainda que disfarçadas, as lógicas e os dispositivos de disciplinamento que pretendemos ultrapassar?

Estranhar domínios de referência teórico-metodológica e técnico-operativa tornou-se, desse modo, fundamental para colocar em cena a experimentação de um modo de produção de conhecimento, no encontro com outros atores e com outros saberes, que permitiu a descoberta dos possíveis caminhos a serem percorridos para que novas formas de habitar o campo sociojurídico fossem inventadas.

\section{Recebido em 3/7/2015 - Aprovado em 15/10/2015}

\section{Referências bibliográficas}

AGUIAR, K. F. de; ROCHA, M. L. da. Pesquisa-intervenção e a produção de novas análises. Psicologia: Ciência e Profissão, Brasília, v. 23, n. 4, p. 64-73, dez. 2003. Disponível em: <http://www.scielo.br/pdf/pcp/v23n4/v23n4a10.pdf >. Acesso em: 28 jan. 2014.

ATUAÇÃO de Assistentes Sociais no Sociojurídico: subsídios para reflexão. Brasília: Conselho Federal de Serviço Social, 2014. 107 p. 
BENEVIDES, R.; PASSOS, E. A humanização como dimensão pública das políticas de saúde. Ciência e Saúde Coletiva, Rio de Janeiro, v. 10, n. 3, p. 561-571, 2005. Disponível em: <http://www.scielo.br/scielo.php?script=sci_arttext\&pid=S141381232005000300014>. Acesso em: 13 jan. 2015.

BOURGUIGNON, J. A. Concepção de rede intersetorial. São Paulo, 2011. Disponível em: <www.uepg.br/nupes/intersetor.htm>. Acesso em: 10 out. 2014.

BRASIL. Lei n. 8.212, de 24 de julho de 1991. Dispõe sobre a organização da Seguridade Social, institui Plano de Custeio e dá outras providências. Diário Oficial [da] República Federativa do Brasil. Brasília, 24 jul. 1991. Disponível em: <http://www. planalto.gov.br/ccivil_03/leis/18212cons.htm>. Acesso em: 6 jan. 2015.

BRASIL. Lei n. 10.406, de 10 de janeiro de 2002. Institui o Código Civil. Diário Oficial [da] República Federativa do Brasil. Brasília, 10 jan. 2002. Disponível em: <http:// www.planalto.gov.br/ccivil_03/leis/2002/110406.htm>. Acesso em: 15 set. 2013.

CARLSON, A. C. R.; PINHEIRO, L. de S. Práticas intersetoriais: novos desafios postos aos psicólogos na atual política de assistência social. In: CRUZ, L. R. da; RODRIGUES, L.; GUARESCHI, N. M. F. (Orgs.). Interlocuções entre a Psicologia e a política nacional de Assistência Social. Santa Cruz do Sul: Edunisc, 2013. p. 103-117.

ESPÍRITO SANTO (Estado). Lei Complementar n. 567, de 21 de julho de 2010. Altera, acrescenta e modifica Títulos, Capítulos e dispositivos da Lei Complementar n. 234, de 18 de abril de 2002 (Código de Organização Judiciária do Estado do Espírito Santo). Vitória, 21 jul. 2010. Disponível em: < hhttp://www.cgj.es.gov.br/arquivos/legislação/ Lei-Complementar-567-2010-Altera-Cod-Organ-Judiciária-(Lei-234).pdf $>$. Acesso em: 2 dez. 2013.

FAGUNDES, H. S.; NOGUEIRA, V. M. R. O princípio da integralidade nas políticas nacionais de saúde e assistência social. In: SEMINÁRIO DE POLÍTICA SOCIAL NO MERCOSUL, 2., Seguridade Social, Participação e Desenvolvimento. Pelotas: Educat, 2008. p. 1-11. Disponível em: <www.uff.br/lassal/images/stories/jornadas/artigo>. Acesso em: 29 set. 2012.

FALK, M. L. R.; RAMOS, M. Z.; SALGUEIRO, J. B. A rede como estratégia metodológica da Política Nacional de Humanização: a experiência de um hospital universitário. Interface - Comunicação, Saúde e Educação, São Paulo, v. 13, p. 709-717, 2009. Disponível em: <http://www.scielo.br/scielo.php?pid=S1414-32832009000500022\& script=sci_arttext $>$. Acesso em: 13 jan. 2015. 
FÁVERO, E. T. O estudo social: fundamentos e particularidades de sua construção na área judiciária. In: CFESS (Org.). O estudo social em perícias, laudos e pareceres técnicos: contribuição ao debate no Judiciário, Penitenciário e na Previdência Social. São Paulo: Cortez, 2007. p. 9-52.

IAMAMOTO, M. V. Questão social, família e juventude: desafios do trabalho do assistente social na área sociojurídica. In: SALES, M. A.; MATOS, M. C. de; LEAL, M. C. Política social, família e juventude: uma questão de direitos. São Paulo: Cortez, 2010. p. 261-298.

MORAES, M.; BERNARDES, A. G. Apresentação. In: BERNARDES, A. G.; TAVARES, G. M.; MORAES, M. Cartas para pensar políticas de pesquisa em psicologia. Vitória: Edufes, 2014. p. 7-14.

NASCIMENTO, M. L. do; SHEINVAR, E. De como as práticas do conselho tutelar vêm se tornando jurisdicionais. Aletheia, Canoas, n. 25, p. 152-162, jan./jun. 2007. Disponível em: <http://www.ulbra.br/psicologia/files/aletheia25.pdf > Acesso em: 20 fev. 2015.

VASCONCELOS, M. de F. F. de; MORSCHEL, A. O apoio institucional e a produção de redes: do desassossego dos mapas vigentes na saúde coletiva. Interface - Comunicação, Saúde e Educação, São Paulo, v. 13, p. 729-738, 2009. Disponível em: <http:// www.scielo.br/scielo.php?script=sci_arttext\&pid=S1414-2832009000500024>. Acesso em: 11 jan. 2015. 